\title{
Efficacy and reliability of the use of a needle grasper to prevent trocar site hernia
}

\author{
Turgut Donmez ${ }^{1}$, Halim Ozcevik ${ }^{2}$, Oguzhan Sunamak ${ }^{3}$, Dogan Yildirim ${ }^{4}$ \\ ${ }^{1}$ Department of General Surgery, Lutfiye Nuri Burat State Hospital, Istanbul, Turkey \\ ${ }^{2}$ Istanbul Provincial Health Directorate, Istanbul, Turkey \\ ${ }^{3}$ Department of General Surgery, Haydarpasa Numune Training and Research Hospital, Istanbul, Turkey \\ ${ }^{4}$ Department of General Surgery, Haseki Training and Research Hospital, Istanbul, Turkey
}

Videosurgery Miniinv 2018; 13 (4): 477-484

DOI: https://doi.org/10.5114/wiitm.2018.75867

\begin{abstract}
Introduction: Port site herniation is one of the serious complications of laparoscopic surgery, which decreases its benefits. Closure of a fascia defect at the port site is an important problem of laparoscopic surgery, especially in obese patients.

Aim: To evaluate needle grasper fascia closure.

Material and methods: We closed the port site fascia using a percutaneous organ-holding device (needle grasper) in laparoscopic cholecystectomy patients. This study included 334 patients who underwent laparoscopic cholecystectomy between January 2015 and January 2017 in our hospital. Patients were divided into 2 fascia closure groups: group 1 with a standard simple suturing technique and group 2 with a needle grasper to close the port site. Patient demographics, operative details, and postoperative outcomes were collected and evaluated.

Results: There were 243 female and 91 male (total 334) patients with the mean age of $49.18 \pm 13.15$ years. Only 1 patient in the $B M I>30 \mathrm{~kg} / \mathrm{m}^{2}$ group of patients had port site hernia development with the needle grasper technique at the end of the 8-month follow-up period. The port site hernia incidence was higher in group 1 than group 2 $(p<0.001)$, but there was no significant difference in terms of operation duration between the two groups $(p<0.001$, $p=0.709$, respectively). In patients with a $B M I>30 \mathrm{~kg} / \mathrm{m}^{2}$, both operation duration and port site hernia incidence were higher in simple suture closure than in the needle grasper technique ( $p<0.001, p=0.016, p=0.005)$.

Conclusions: The needle grasper technique is easy, simple, safe, fast, and effective for fascia closure of port sites. This method can also be applied in obese patients easily, safely and in a short time.
\end{abstract}

Key words: laparoscopic cholecystectomy, needle grasper, port site hernia.

\section{Introduction}

Laparoscopic surgery is a widely used surgical practice because of its minimal invasiveness and advantages [1, 2]. An incisional hernia at the site of trocar entry (port site hernia) is a serious complication of laparoscopic surgery requiring surgical repair [3]. The port site hernia (PSH) depends on the trocar diameter, the trocar design, pre-existing fascial defects, high body mass index (BMI), increased intra-abdominal pressure, increased abdominal wall thickness, wound infection and the direction of the port insertion. The risk of PSH is greater in obese patients because of larger preperitoneal space and increased intra-abdominal pressure, and some authors suggest repair of defects bigger than $5 \mathrm{~mm}$ on

\section{Address for correspondence}

Turgut Donmez MD, Department of General Surgery, Lutfiye Nuri Burat State Hospital, 34300 Istanbul, Turkey, phone: +90 5347400967, e-mail: surgeont73@hotmail.com 
the fascia [4-6]. Port-site herniation might lead to small bowel obstruction and incarceration if untreated [7]. It was reported that laparoscopic port site hernias can occur with incisions as small as $3 \mathrm{~mm}$ [8]. It is recommended that the fascia of $10 \mathrm{~mm}$ or wider trocar sites in adults and $5 \mathrm{~mm}$ or wider port sites in children must be closed [9-11]. Complete closure of fascia at the port site can be complicated and frustrating, often requiring blind suturing of the fascial defect, with the risks of incomplete closure and injury to the intraperitoneal organs or larger skin incisions.

\section{Aim}

In this study, we evaluated a promising technique of primary suture repair for safety, feasibility, and complete closure of the abdominal fascia at the port site.

\section{Material and methods}

We analyzed the patients admitted to the general surgery outpatient or emergency departments of a state hospital with 100 beds with abdominal pain or dyspeptic complaints between January 2015 and January 2017, retrospectively. Three hundred and thirty-four patients (243 female, 91 male) who underwent multiport cholecystectomy because of acute cholecystitis or cholelithiasis, gallbladder polyp, or gallbladder sludge were included in the study. All operations were performed by experienced surgeons after obtaining detailed written informed consent. Patients were divided into two groups: group 1 of 196 laparoscopic cholecystectomy (LC) patients operated on with the standard technique to close the port site and group 2 of 138 LC patients operated on with a needle grasper to close the port site. The study protocol conformed to the ethical guidelines of the Declaration of Helsinki as reflected in prior approval by the institution's human research committee. The study was approved by the Local Hospital Ethics Committee (date: October 4, 2017 no. 560).

All patients underwent abdominal ultrasound, and benign gallbladder disease was confirmed. Patients with previous abdominal surgery, pregnant women, those with bleeding diathesis, and patients with a diagnosis of gallbladder cancer were excluded.

All patients were analyzed in terms of age, sex, height, weight, BMI, comorbid diseases, operative time, conversion to laparotomy, drain use, port site hernia, complications, and length of hospital stay. All patients were operated on under general anesthesia by the same surgeon using two different techniques.

\section{Surgical techniques}

The patients of both groups underwent conventional standard LC under general anesthesia. We used a 4-trocar technique; three $5 \mathrm{~mm}$ trocars, one $10 \mathrm{~mm}$ trocar and a $5 \mathrm{~mm}$ zero degree optical camera. A $10 \mathrm{~mm}$ trocar port was placed in the subxiphoid region and the gallbladder was extracted from the abdominal cavity through this subxiphoid trocar and after extraction the fascia was sutured.

The simple fascia closure technique was used in group 1 where following the laparoscopic procedure, pneumoperitoneum was evacuated out of the abdominal cavity and with the help of retractors, a round-needle suture (Vicryl 1-0, Covidien) was passed through both cut edges of the fascia and tied, closing the fascia for closure of the subxiphoid trocar site, and 2 consecutive suture lines with a $3 \mathrm{~mm}$ interval and $5 \mathrm{~mm}$ inside the fascial edge were done. If the fascial defect was widened due to difficulty in extracting a gallbladder with a big stone, three consecutive suture lines with a $3 \mathrm{~mm}$ interval were passed.

In group 2, a needle grasper (Mediflex, Iceland) was used to close the fascia defect (Photo $1 \mathrm{~A}$ ). This was a 14-gauge, $15 \mathrm{~cm}$ long tool which had a metal open needle on its tip, and when the button on its top was pressed, a thin grasper went out (Photos $1 \mathrm{~B}, \mathrm{C})$. Here, following completion of the laparoscopic procedure, the tip of the suture string (Vicryl 1-0, Covidien) was held with the needle grasper and pulled inside of the tool. The needle grasper schematic view of the skin and the passage of the fascia is presented (Figures $1 \mathrm{~A}-\mathrm{C}$ ). The $10 \mathrm{~mm}$ trocar was removed and the right hand of the surgeon inserted the needle grasper through the $10 \mathrm{~mm}$ port hole until the fascia while the point finger of the left hand of the surgeon obliterated the port hole to keep the pneumoperitoneum inside. Under direct vision of the optical camera, the needle grasper was inserted through the fascia approximately $5 \mathrm{~mm}$ inside of the cut edge and advanced it until $2 \mathrm{~mm}$ of its tip entered the abdominal cavity (Photo $2 \mathrm{~A}$ ). Then, the needle grasper was opened by pressing the button on the top of it and the tip of the suture thread was released inside of the abdomen, the needle grasp- 

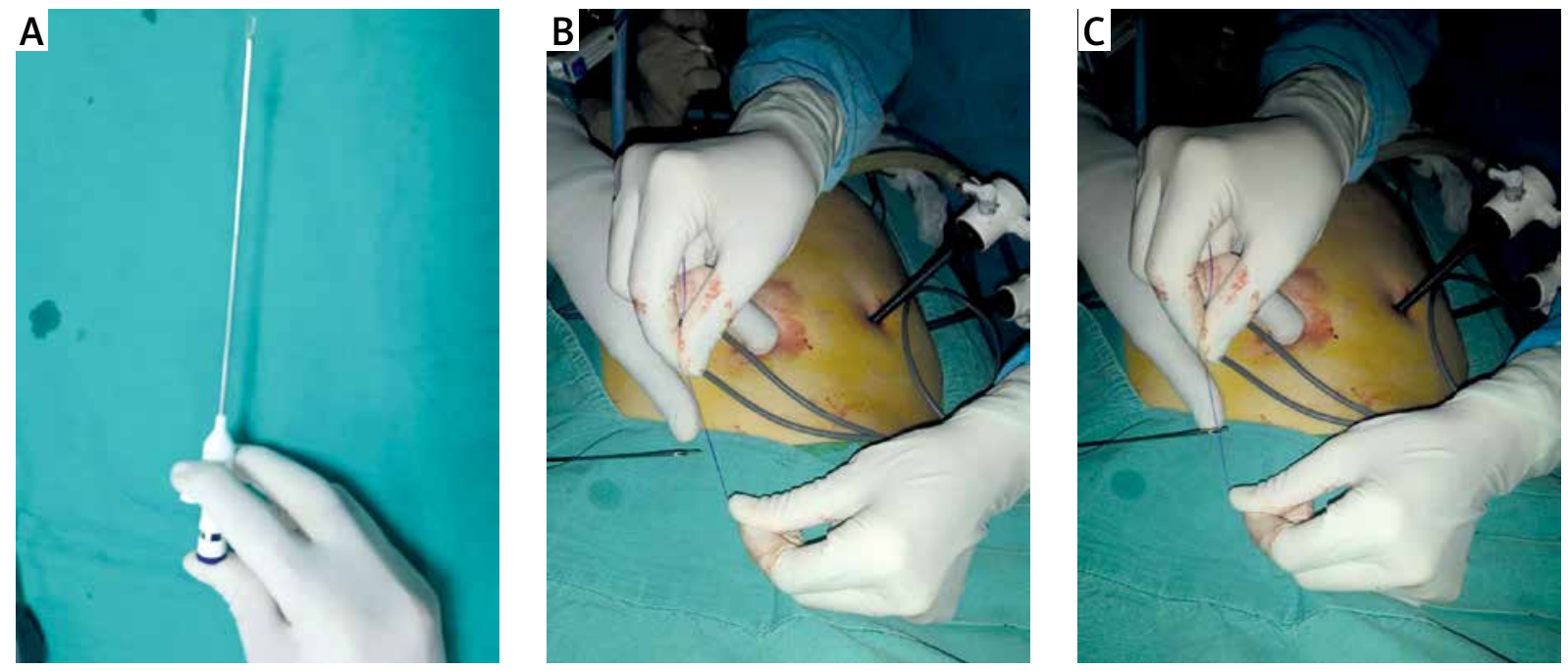

Photo 1. A - Needle grasper device. B - Needle grasper and 1/0 vicryl suture string. C - Catching of 1/0 vicryl suture string with needle grasper and pulling it into the needle grasper
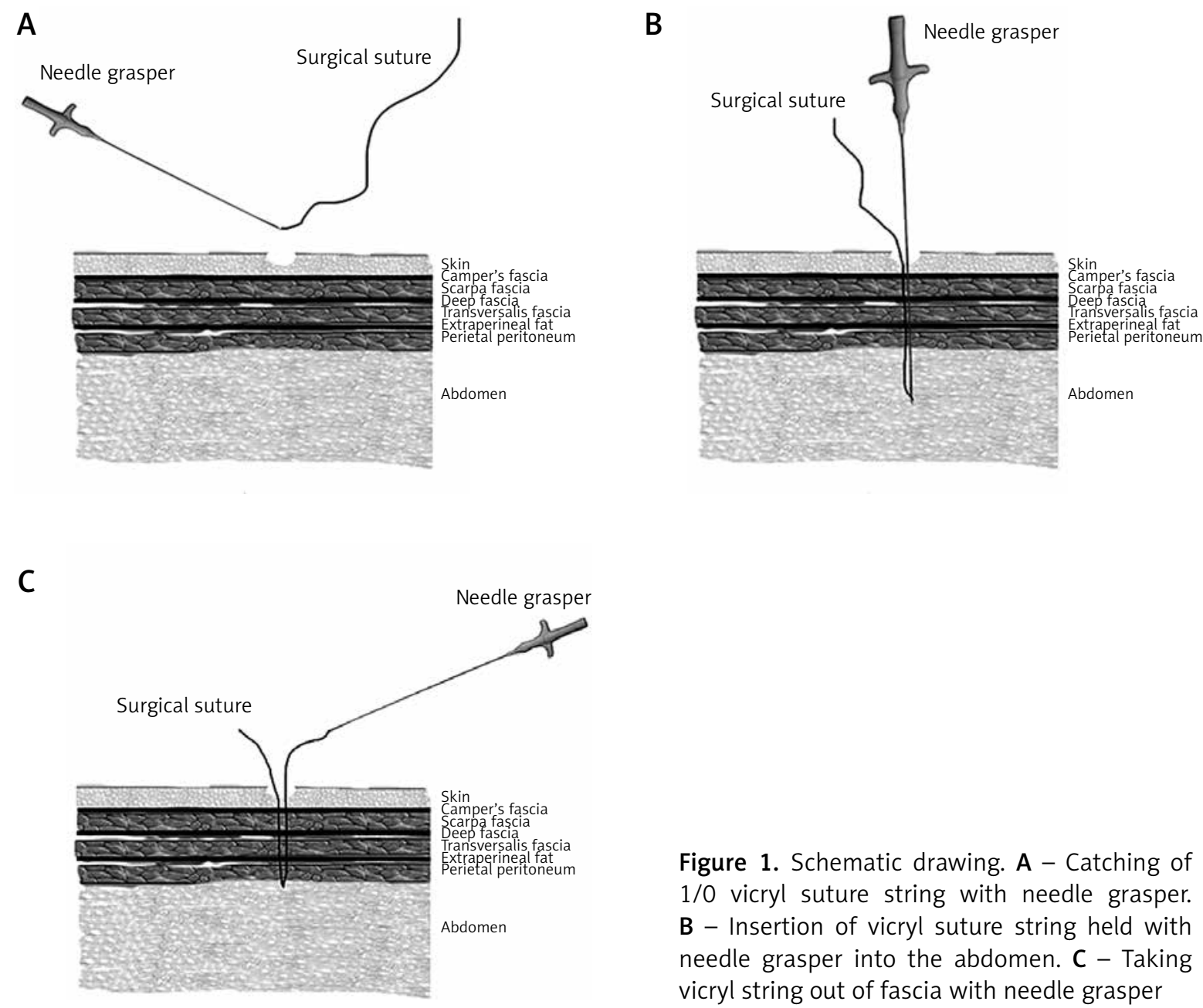

Figure 1. Schematic drawing. A - Catching of $1 / 0$ vicryl suture string with needle grasper. B - Insertion of vicryl suture string held with needle grasper into the abdomen. C - Taking vicryl string out of fascia with needle grasper 

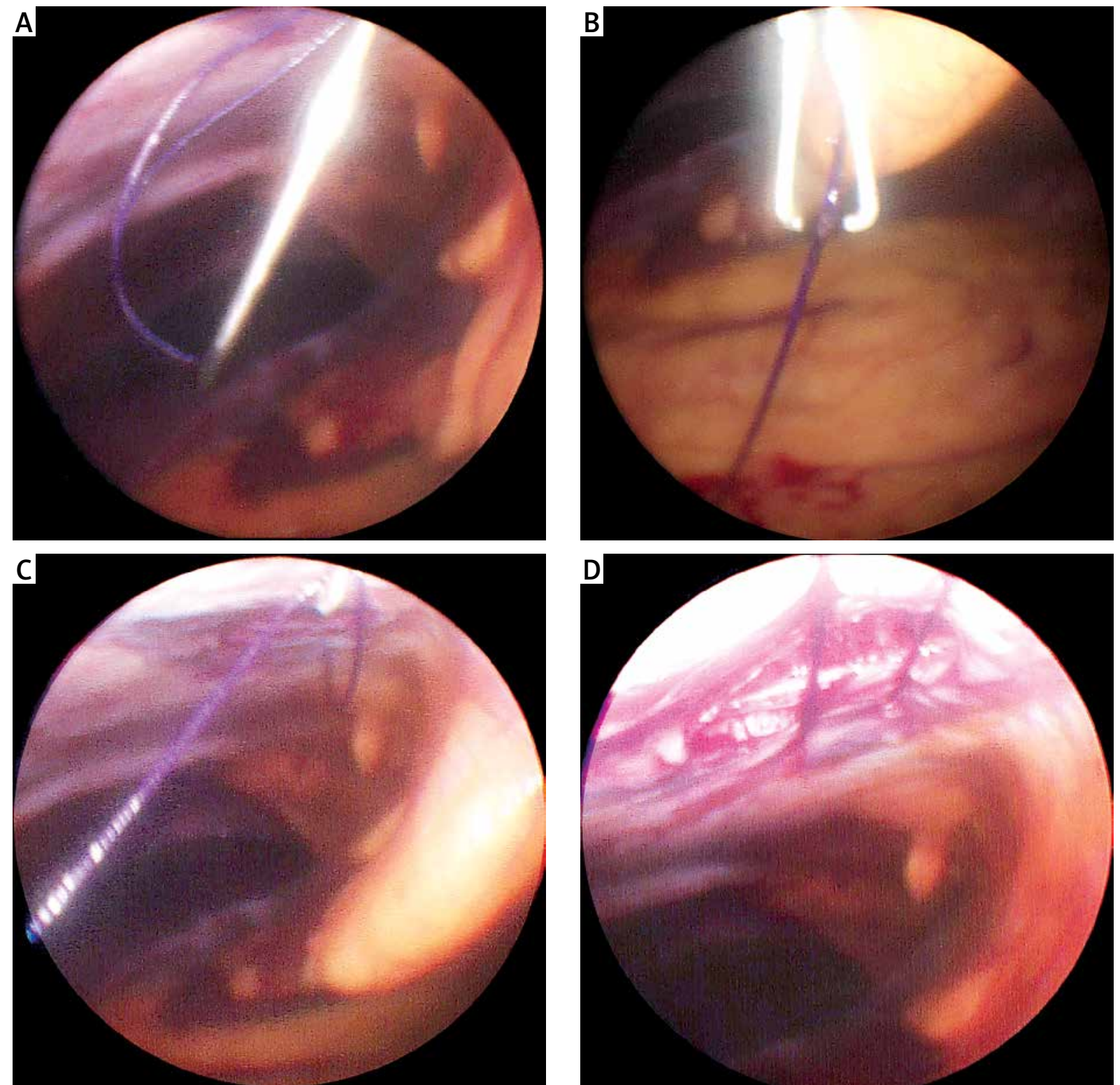

Photo 2. A - Insertion of vicryl suture string held with needle grasper into the abdomen. B - Needle grasper - catching of the suture string inserted using the needle grasper on the opposite side of the fascia. $\mathbf{C}$ - Taking vicryl string out of fascia with needle grasper. D - Two lines of vicryl suture string placed on the fascia

er was retrieved and inserted again $5 \mathrm{~mm}$ inside of the cut edge of the fascia at the opposite side, the released tip of the suture string was caught with the needle grasper (Photo 2 B), then the grasper was closed and taken out through the port hole slowly (Photo 2 C). The tip of the string was then released, and two tips were tied between each other to close the fascia defect (Photo 2 D). The mean duration for one complete suture placement on the fascia was $\times 2 \mathrm{~min}$ in the needle grasper technique. If neces- sary, another line of suture was applied in the same manner.

\section{Statistical analysis}

The program SPSS 15.0 for Windows was used for statistical analysis. For descriptive statistics and categorical variables, we used numbers and percentages. For numerical variables, the mean, standard deviation, minimum, and maximum were used. Student's $t$-test was used in conditions where numeri- 
cal variables were distributed equally between the groups; the Mann-Whitney $U$ test was used for dissimilar distributions. Categorical variables between groups were analyzed using the $\chi^{2}$ test. Monte Carlo simulation was used for the tables with more than two chambers where the conditions for parametric test could not be provided. The $\alpha$ value of statistical significance was accepted as $p<0.05$.

\section{Results}

One hundred and forty-seven female and 49 male patients in group 1 and 96 female and 42 male patients in group 2 were enrolled in the study. There was no statistically significant difference in terms of age, height, weight, BMI or ASA scores between the groups (Table I). There were no statistically significant differences in terms of comorbidities, analgesic requirement, bleeding, infection, or hematoma incidences (Table I).

The mean operative time and port site hernia rate in group 1 were significantly higher than in group 2 ( $p=0.016, p=0.014)$. The proportion of patients having a $\mathrm{BMI}>30 \mathrm{~kg} / \mathrm{m}^{2}$ was higher in group 2 than group 1 ( $p=0.007)$.

The mean follow-up period of the patients having a $\mathrm{BMI}>30 \mathrm{~kg} / \mathrm{m}^{2}$ in group 2 was longer than that of group 1 and port site hernia incidence in group 1 was higher than that of group $2(p=0.001$ and $p=$ 0.006 , respectively) (Table II). There were no significant differences in terms of age, operation duration, hematoma or bleeding (Table II).

\section{Discussion}

Port site hernias are one of the early and late complications of laparoscopic surgery [12]. This type of hernia might be seen as early as a few hours to 18 months after surgery [13-16]. The small bowel or omentum might be trapped in these hernias, resulting in incarceration. Owens et al. reported that $52.1 \%$ of the port site hernias presented with small bowel obstruction or strangulation [1].

Port site hernias were reported to have originated from the umbilical port or ports placed on the midline [12-18]. The most efficient method to prevent this risk is to repair the fascia defect, especially for $10 \mathrm{~mm}$ or wider port sites [3].

Meticulous closure of laparoscopic port sites is important to prevent PSH and its complications. If the fascia is not closed properly, infection or suture disruption occurs, PSH might develop or fluid fistula might occur in patients with ascites $[19,20]$.

Shaher classified port closure techniques in three groups: 1) techniques necessitating assistance from the inside of the abdomen which requires 2 additional ports; 2) the use of extracorporeal assistance requiring one additional port; and 3 ) techniques which can be used with or without visualization which need no additional port. He reported that most of these techniques necessitate special devices, some of which are time consuming and/or need intra-abdominal help [21].

The literature lacks data comparing the operation time for port site hernias. We did not find any significant difference in terms of operation duration between the two groups though it was shorter in group 2 in our study. The shorter operation duration in group 2 shows that this procedure is performed more easily and in a shorter time.

Analyzing the operation duration of the patients with a $\mathrm{BMI}>30 \mathrm{~kg} / \mathrm{m}^{2}$, it was significantly shorter in group 2 than in group $1(p=0.016)$. This difference might be related to difficulty in passing fascia sutures in obese patients because of thicker subcutaneous fat tissue. We can say that fascia closure with the needle grasper made the operation duration shorter in our study.

Some fascia closure devices such as the spinal needle, hypodermic needle, Deschamps needle, and aneurysm needle were suggested to close the fascia defect with 0-1\% PSH incidence [22-26]. However, all these procedures are unsuitable in obese cases because of the thick abdominal wall and oblique wound necessitating assistance from inside; the suture is placed from the port site, which requires an increased skin incision, and the suture passes close to the edges of the fascia defect. Lasheen et al. reported percutaneous transabdominal technique for closure of the port site with no port site herniation [10, 11]. However, this technique cannot be used in obese patients. Also, it is more invasive when the two suture strands are brought to the port site by redirecting the suture hook or by direct subcutaneous dissection.

There are studies on simple techniques to repair a port site defect. Hamayora sutured the fascia defect under direct vision using an S retractor in their prospective clinical study of 100 patients and emphasized that it is a cheap and effective technique. However, they did not report patient distribution, the obese/non-obese ratio or recurrence [27]. Lasheen 
Table I. Demographic characteristics of patients and operative data

\begin{tabular}{|c|c|c|c|}
\hline Parameter & Group 1 & Group 2 & $P$-value \\
\hline \multicolumn{4}{|l|}{ Gender: } \\
\hline Female & $147(75.0 \%)$ & $96(69.6 \%)$ & 0.272 \\
\hline Male & 49 (25.0\%) & $42(30.4 \%)$ & \\
\hline Age, mean \pm SD (min.-max.) & $49.3 \pm 13.6(18-80)$ & $49.0 \pm 12.6(19-76)$ & 0.812 \\
\hline Height, mean \pm SD (min.--max.) & $166.4 \pm 7.3(150-186)$ & $166.1 \pm 7.8(155-185)$ & 0.389 \\
\hline Weight, mean \pm SD (min.-max.) & $77.2 \pm 11.5(50-110)$ & $77.2 \pm 11.9(51-105)$ & 0.905 \\
\hline BMI, mean \pm SD (min.-max.) & $27.8 \pm 3.7(18.8-38.5)$ & $28.0 \pm 4.4(17.6-39.1)$ & 0.761 \\
\hline \multicolumn{4}{|l|}{ BMI [kg/m²]: } \\
\hline$\leq 30$ & $154(78.6 \%)$ & $90(65.2 \%)$ & 0.007 \\
\hline$>30$ & $42(21.4 \%)$ & $48(34.8 \%)$ & \\
\hline \multicolumn{4}{|l|}{ ASA: } \\
\hline 1 & $132(67.3 \%)$ & $100(72.5 \%)$ & 0.371 \\
\hline 2 & $54(27.6 \%)$ & $29(21.0 \%)$ & \\
\hline 3 & $10(5.1 \%)$ & $9(6.5 \%)$ & \\
\hline Operation duration, mean \pm SD (min.-max.) & $51.0 \pm 7.6(39-67)$ & $50.3 \pm 7.8(38-65)$ & 0.709 \\
\hline Analgesics, mean \pm SD (min.-max.) & $4.36 \pm 0.59(4-6)$ & $4.33 \pm 0.56(4-6)$ & 0.728 \\
\hline Infection & $6(3.1 \%)$ & $5(3.6 \%)$ & 0.766 \\
\hline Hematoma & $3(1.5 \%)$ & $2(1.4 \%)$ & 1.000 \\
\hline COPD & $26(13.3 \%)$ & $18(13.0 \%)$ & 1.000 \\
\hline HT & $40(20.4 \%)$ & $22(15.9 \%)$ & 0.301 \\
\hline DM & $41(20.9 \%)$ & $33(23.9 \%)$ & 0.516 \\
\hline \multicolumn{4}{|l|}{ Comorbidity: } \\
\hline None & $128(65.3 \%)$ & $92(66.7 \%)$ & 0.582 \\
\hline $\mathrm{DM}$ & $17(8.7 \%)$ & $18(13.0 \%)$ & \\
\hline $\mathrm{DM}+\mathrm{HT}$ & $13(6.6 \%)$ & $7(5.1 \%)$ & \\
\hline $\mathrm{DM}+\mathrm{HT}+\mathrm{COPD}$ & $3(1.5 \%)$ & $2(1.4 \%)$ & \\
\hline $\mathrm{DM}+\mathrm{COPD}$ & $6(3.1 \%)$ & $5(3.6 \%)$ & \\
\hline $\mathrm{HT}$ & $10(5.1 \%)$ & $2(1.4 \%)$ & \\
\hline $\mathrm{HT}+\mathrm{DM}$ & $2(1.0 \%)$ & $1(0.7 \%)$ & \\
\hline $\mathrm{HT}+\mathrm{COPD}$ & $12(6.1 \%)$ & $10(7.2 \%)$ & \\
\hline COPD & $5(2.6 \%)$ & $1(0.7 \%)$ & \\
\hline Port site hernia & $17(8.7 \%)$ & $1(2.2 \%)$ & 0.001 \\
\hline Bleeding & $5(2.6 \%)$ & $2(1.4 \%)$ & 0.704 \\
\hline Follow-up time, mean \pm SD (min.-max.) & $21.9 \pm 6.6(10-33)$ & $22.7 \pm 6.7(10-33)$ & 0.308 \\
\hline
\end{tabular}


Table II. BMI > $30 \mathrm{~kg} / \mathrm{m}^{2}$ patient data

\begin{tabular}{|lccccc|}
\hline Parameter & \multicolumn{2}{c}{ Group 1 } & \multicolumn{2}{c|}{ Group 2 } & P-value \\
\cline { 2 - 5 } & Mean \pm SD & Min.-max. & Mean \pm SD & Min.-max. \\
\hline Age & $49.9 \pm 14.0$ & $19-74$ & $50.2 \pm 13.3$ & $19-76$ & 0.923 \\
\hline Operation duration & $52.3 \pm 8.2$ & $38-68$ & $50.2 \pm 8.2$ & $38-67$ & 0.016 \\
\hline Follow-up time & $19.6 \pm 5.5$ & $10-32$ & $23.8 \pm 6.1$ & $11-33$ & 0.001 \\
\hline & $n$ & $\%$ & $n$ & $\%$ & 1.000 \\
\hline Hematoma & 0 & 0.0 & 1 & 2.1 & 0.005 \\
\hline Port site hernia & 10 & 23.8 & 1 & 4.2 & 0.098 \\
\hline Bleeding & 3 & 7.1 & 0 & 0.0 & \\
\hline
\end{tabular}

et al. used a Lasheen needle to close $10 \mathrm{~mm}$ port size defects and reported no PSH, but wound infection occurred in 3 of the patients in their prospective clinical study [28]. Ng reviewed the application of a number of simple techniques but did not give information about PSH incidence of these techniques [29].

Nassar et al. in their clinical study on fascia closure with suture reported $12 \%$ PSH incidence. They used a simple suture fascia closure technique with absorbable suture in $90 \%$ of the patients. They reported that non-absorbable suture use in fascia defects wider than $2 \mathrm{~cm}$ can prevent hernia development [16].

Lambertz et al. in their two-center retrospective clinical study of 54 patients in 2017 analyzed 41 and 13 patients in whom simple suture technique and mesh closure were used, respectively and found PSH development in 52 (96\%) cases [30]. They emphasized that $\mathrm{PSH}$ development risk is directly related to $\mathrm{BMI}$ and diameter of the fascia defect. We found that PSH incidence was higher in patients with $\mathrm{BMI}>30 \mathrm{~kg} / \mathrm{m}^{2}$ compared to the patients with $\mathrm{BMI}<30 \mathrm{~kg} / \mathrm{m}^{2}$ in the simple suture group (23.8\% vs. $4.54 \%$ ) [31].

There are numerous studies on port site hernia development, and omentum and small bowel strangulation in it, following laparoscopic surgery. However, Singal et al. reported no hernia development for closure with both the simple suture and no closure groups in their prospective randomized LC series of 200 non-obese patients at the end of the 8-month follow-up [31].

We used a needle grasper in its position and by obstructing the port hole with a finger, kept the pneumoperitoneum under direct visualization in group 2 through the $10 \mathrm{~mm}$ epigastric port, eliminat- ing the need of another port for intra-abdominal assistance. Our technique is less invasive as it does not necessitate subcutaneous dissection to take suture tips out of the port hole. This technique is suitable for good closure of any port type (camera, working, single ports) for any case. Our technique is easily applicable to obese and morbidly obese patients. Other techniques proposed necessitate the help of additional hand tools for intra-abdominal assistance, and their applicability in obese patients is difficult [22-25]. Extending the skin incision might be necessary, and fascia repair in obese patients is difficult with techniques using simple suture closure.

We used this technique to close the fascial defect of umbilical port entry in our two-port laparoscopic appendectomy study of 34 cases and did not observe any PSH development [32]. This technique can be used safely to close $10 \mathrm{~mm}$ or bigger trocar entry-dependent fascial defects in all laparoscopic intra-abdominal operations.

We found that the needle grasper technique had significantly lower incidence of PSH development compared to simple suture closure technique (respectively $p=0.001$ and $p=0.005$ ). For the nonobese patients, none of the patients in the needle grasper group, but seven in the simple closure group, had PSH. Only one patient in the BMI > $30 \mathrm{~kg} / \mathrm{m}^{2}$ group of patients had PSH with the needle grasper technique, which was observed on the $3^{\text {rd }}$ post operative day, and the patient was a COPD patient having severe cough attacks. On the other hand, 10 patients with simple suture closure technique had PSH in the same group. We thought that the reason for this was insufficient closure of the fascia because of excess subcutaneous fat tissue in obese patients. 
In this group of patients, reaching and suturing the fascia is difficult, thus making it prone to hernia development.

\section{Conclusions}

The needle grasper fascia closure technique is easier, safer and more efficient to prevent PSH development and takes less time to perform compared to the simple closure technique in laparoscopic surgery. We believe that we can prevent postoperative port site hernia development by using the needle grasper closure technique.

\section{Conflict of interest}

The authors declare no conflict of interest.

\section{References}

1. Owens M, Barry M, Janjua AZ, et al. A systematic review of laparoscopic port-site hernias in gastrointestinal surgery. Surgeon 2011; 9: 218-24

2. Swank HA, Mulder IM, la Chapelle CF, et al. Systematic review of trocar-site hernia. Br J Surg 2012; 99: 315-23.

3. Azurin DJ, Go LS, Arroyo LR, et al. Trocar site herniation follow ing laparoscopic cholecystectomy and the significance of an in cidental preexisting umbilical hernia. Am Surg 1995; 61: 718-20.

4. Shah PR, Naguib N, Thippeswammy K, et al. Port site closure after laparoscopic surgery. J Minim Access Surg 2010; 6: 22-3.

5. Hussain A, Mahmood H, Singhal T, et al. Long-term study of port-site incisional hernia after laparoscopic procedures. JSLS 2009; 13: 346-9.

6. Botea F, Torzilli G, Sarbu V. A simple, effective technique for port-site closure after laparoscopy. JSLS 2011; 15: 77-80.

7. Tangjaroen S, Watanapa P. Unclosed fascial defect: is it the risk to develop port-site hernia after laparoscopic cholecystectomy? J Med Assoc Thai 2014; 97: 191-4.

8. Bergemann JL, Hibbert ML, Harkins G, et al. Omental herniation through a $3 \mathrm{~mm}$ umbilical trocar site: unmasking a hidden umbilical hernia. J Laparoendosc Adv Surg Tech A 2001; 11: 171-3.

9. Tonouchi H, Ohmori Y, Kobayashi M, et al. Trocar site hernia. Arch Surg 2004; 139: 1248-56.

10. Lasheen AE, Salem A, Abd Elaal S, et al. Percutaneous trans-abdominal external looped needle with two holes in the trocar sheath for port-site closures in difficult obese cases. Asian J Endosc Surg 2016; 9: 295-9.

11. Lasheen AE, Safwat K, Elsheweal A, et al. Effective, simple, easy procedure for laparoscopic port closure in difficult cases. Ann Med Surg 2016; 10: 36-40.

12. Boldo E, Perez de Lucia G, Aracil JP, et al. Trocar site hernia after laparoscopic ventral hernia repair. Surg Endosc 2007; 21: 798800.

13. Plaus WJ. Laparoscopic trocar site hernias. J Laparoendosc Surg 1993; 3: 567-70.
14. Sanz-Lopez R, Martınez-Ramos C, Nunez-Pena JR, et al. Incisional hernias after laparoscopic vs open cholecystectomy. Surg Endosc 1999; 13: 922-4.

15. Bowrey DJ, Blom D, Crookes PF, et al. Risk factors and the prevalence of trocar site herniation after laparoscopic fundoplication. Surg Endosc 2001; 15: 663-6.

16. Nassar AH, Ashkar KA, Rashed AA, et al. Laparoscopic cholecystectomy and the umbilicus. Br J Surg 1997; 84: 630-3.

17. Di Lorenzo N, Coscarella G, Lirosi F, et al. Trocars and hernias: a simple, cheap remedy. Chir Ital 2005; 57: 87-90.

18. Mayol J, Garcia-Aguilar J, Ortiz-Oshiro E, et al. Risk of the minimal access approach for laparoscopic surgery: multivariate analysis of morbidity related to umbilical trocar insertion. World J Surg 1997; 21: 529-33.

19. Fear R. Laparoscopy, a valuable aid in gynecologic diagnosis. Obstet Gynecol 1968; 31: 297.

20. Aziz HH. A simple technique of laparoscopic port closure. JSLS 2013; 17: 672-4.

21. Shaher Z. Port closure techniques. Surg Endosc 2007; 21: 1264-74.

22. Critchlow JT. Trocar site closure: a simple, inexpensive technique. JSLS 1997; 1: 273-5.

23. Chung RS. Closure of trocar wounds in laparoscopic operations. Surg Endosc 1995; 9: 534-6.

24. Di Lorenze N, Coscarella G, Lirosi F, et al. Port site closure: a new problem, an old device. JSLS 2002; 6: 181-3.

25. Rajendiran A, Maruthupandian D, Karunakaran K, et al. Aneurysm needle as an effective tool in laparoscopic port closure. J Laparoendosc Adv Surg Tech A 2015; 25: 744-6.

26. Hussain A, Mahmoud $H$, Singhal $T$, et al. Long term study of port site incisional hernia after laparoscopic procedures. JSLS 2009; 13: 346-9.

27. Hamayora HA. A simple technique of laparoscopic port closure. JSLS 2013; 17: 672-4.

28. Lasheen A, Safwat H, Fiad A, et al. Port-site closure using a modified aptos needle. JSLS 2013; 17: 312-5.

29. Ng WG. A full review of port-closure techniques. Surg Endosc 2007; 21: 1895-7.

30. Lambertz A, Stüben BO, Bock B, et al. Port-site incisional hernia - a case series of 54 patients. Ann Med Surg 2017; 14: 8-11.

31. Singal R, Zaman M, Mittal A, et al. No need of fascia closure to reduce trocar site hernia rate in laparoscopic surgery: a prospective study of 200 non-obese patients. Gastroenterology Res 2016; 9: 70-3.

32. Donmez T, Sunamak O, Ferahman S, et al. Two-port laparoscopic appendectomy with the help of a needle grasper: better cosmetic results and fewer trocars than conventional laparoscopic appendectomy. Videosurgery Miniinv 2016; 11: 105-10.

Received: 6.02.2018, accepted: 19.03.2018. 